\title{
Combining Oxymatrine or Matrine with Lamivudine Increased Its Antireplication Effect against the Hepatitis B Virus In Vitro
}

\author{
Zhi-Jie Ma, ${ }^{1,2}$ Qi Li, ${ }^{1}$ Jia-Bo Wang, ${ }^{1}$ Yan-Ling Zhao, ${ }^{1}$ Yan-Wei Zhong, ${ }^{3}$ \\ Yun-Feng Bai, ${ }^{4}$ Rui-Lin Wang, ${ }^{4}$ Jian-Yu Li, ${ }^{4}$ Hui-Yin Yang, ${ }^{4}$ Ling-Na Zeng, ${ }^{1}$ Shi-Biao Pu, \\ Fei-Fei Liu, ${ }^{1}$ Da-Ke Xiao, ${ }^{5}$ Xin-Hua Xia, ${ }^{6}$ and Xiao-He Xiao ${ }^{4}$ \\ ${ }^{1}$ China Military Institute of Chinese Medicine, 302 Military Hospital, Beijing 100039, China \\ ${ }^{2}$ College of Traditional Chinese Medicine, Chengdu University of Traditional Chinese Medicine, Chengdu, Sichnan 610075, China \\ ${ }^{3}$ Pediatric Liver Disease Therapy and Research Center, 302 Military Hospital, Beijing 100039, China \\ ${ }^{4}$ Integrative Medical Center, 302 Military Hospital, No. 100 4th Ring Road, Beijing 100039, China \\ ${ }^{5}$ College of Pharmacy, China Pharmaceutical University, Nanjing, Jiangsu 211198, China \\ ${ }^{6}$ College of Pharmacy, Hunan University of Chinese Medicine, Changsha, Hunan 410208, China
}

Correspondence should be addressed to Jia-Bo Wang; pharm_sci@126.com and Xiao-He Xiao; pharmacy302@126.com

Received 1 September 2012; Revised 5 December 2012; Accepted 19 December 2012

Academic Editor: Jae Youl Cho

Copyright (C) 2013 Zhi-Jie Ma et al. This is an open access article distributed under the Creative Commons Attribution License, which permits unrestricted use, distribution, and reproduction in any medium, provided the original work is properly cited.

\begin{abstract}
Some recent clinical reports have shown that the combination of oxymatrine, a phyto-derived drug, with lamivudine (3TC) could improve its curative effect against hepatitis B virus (HBV) infection. However, the experimental data in support of this combination strategy are lacking. In this study, we investigated the anti-HBV activity of the combination of 3TC and either oxymatrine or matrine on HepG2 2.2.15 in vitro. The activities of the combination and the solo compound, each in different concentrations, were compared on the 3rd, 6th, and 9th experimental days. The cytotoxicity results showed that the nontoxic concentrations of both oxymatrine and matrine to HepG2 2.2 .15 cells were $800 \mu \mathrm{g} / \mathrm{mL}$. We found that the single use of oxymatrine below $100 \mu \mathrm{g} / \mathrm{ml}$, matrine below $200 \mu \mathrm{g} / \mathrm{ml}$, and 3TC below $30 \mu \mathrm{g} / \mathrm{ml}$ showed weak inhibitory effects on the secretion of hepatitis B surface antigen (HBsAg), hepatitis B e antigen (HBeAg), and HBV-DNA in culture media; the combination of $3 \mathrm{TC}(30 \mu \mathrm{g} / \mathrm{ml})$ with oxymatrine $(100 \mu \mathrm{g} / \mathrm{ml})$ or matrine $(100 \mu \mathrm{g} / \mathrm{ml})$ showed significant inhibitory effects that were higher than or equivalent to the single use of $3 \mathrm{TC}$ at $100 \mu \mathrm{g} / \mathrm{ml}$. The results provide a new impetus to develop novel, multicomponent anti-HBV drugs through the combination of natural products with nucleoside analogs to enhance their activity.
\end{abstract}

\section{Introduction}

Infection with hepatitis B virus (HBV) is a critical health problem worldwide. Despite the existence of HBV vaccines, approximately $5 \%$ of the world population is infected by HBV. China has the largest population of HBV-infected people in the world and is confronting this large disease burden with efficient antiviral drugs. Although there are several new anti-HBV drugs, such as entecavir and tenofovir, which have been recently developed in western countries, there are still challenges to be faced ahead of the widespread adoption of these new drugs in China due to cost constraints. Lamivudine (3TC), formerly one of the widely used nucleos(t)ide analogs (NAs), is no longer recommended as a first line therapy for HBV infection in the guidelines of both the American Association for the Study of Liver Diseases (AASLDs) [1, 2] and the European Association for the Study of the Liver (EASL) $[3,4]$ due to its defects, such as the emergence of 3TC-resistanant HBV. However, 3TC is still frequently used in China due to its lower price point; this is especially true for the undeveloped regions of China. Obviously, there would be problems with the single use of 3TC; as has been reported in the literature, a single-therapy treatment employing solely 3TC may result in the emergence of both viral drug-resistance and dose-dependent side effects [5].

Under this circumstance, some physicians have attempted to use combinations of traditional Chinese medicines (TCMs) with 3TC to enhance its curative effect. Moreover, 
TABLE 1: Clinical data of the combinational use of oxymatrine with 3TC for the treatment of HBV infection.

\begin{tabular}{|c|c|c|c|c|c|c|}
\hline Data sources & Groups and dosages & $\begin{array}{l}\text { Number of } \\
\text { cases }\end{array}$ & $\begin{array}{l}\text { Course of } \\
\text { treatment } \\
\text { (months) }\end{array}$ & $\begin{array}{c}\text { Rate of ALT } \\
\text { normalization (\%) }\end{array}$ & $\begin{array}{l}\text { Rate of HBeAg negative } \\
\text { conversion }(\%)\end{array}$ & $\begin{array}{c}\text { Rate of HBV-DNA } \\
\text { negative conversion (\%) }\end{array}$ \\
\hline \multirow{2}{*}{ Song [6] } & $3 \mathrm{TC}\left(100^{\#}\right)+\operatorname{Omt}(400)$ & 32 & 3 & 78.1 & 46.9 & 90.6 \\
\hline & $3 \mathrm{TC}(100)$ & 30 & 3 & 50.0 & 16.7 & 86.7 \\
\hline \multirow{2}{*}{ Fan [7] } & $3 \mathrm{TC}(100)+\operatorname{Omt}(400)$ & 32 & 3 & 25 & 15 & 29 \\
\hline & $3 \mathrm{TC}(100)$ & 30 & 3 & 15 & 5 & 26 \\
\hline \multirow{2}{*}{ Duan $[8]$} & $3 \mathrm{TC}(100)+\operatorname{Omt}(600)$ & 60 & 6 & - & 53.3 & 63.3 \\
\hline & $3 \mathrm{TC}(100)$ & 60 & 6 & - & 18.3 & 23.3 \\
\hline \multirow{2}{*}{ Zhang [9] } & $3 \mathrm{TC}(100)+\operatorname{Omt}(600)$ & 62 & 6 & - & 53.23 & 62.90 \\
\hline & $3 \mathrm{TC}(100)$ & 62 & 6 & - & 19.35 & 24.19 \\
\hline \multirow{2}{*}{ Xie [10] } & $3 \mathrm{TC}(100)+\operatorname{Omt}(150)$ & 78 & 6 & 100 & 53.8 & 55.1 \\
\hline & $3 \mathrm{TC}(100)$ & 42 & 6 & 90.5 & 45.2 & 47.6 \\
\hline \multirow{2}{*}{ Liu [11] } & $3 \mathrm{TC}(100)+\operatorname{Omt}(400)$ & 31 & 12 & 100 & 61.3 & 87.1 \\
\hline & $3 \mathrm{TC}(100)$ & 34 & 12 & 100 & 37.1 & 85.7 \\
\hline \multirow{2}{*}{$\mathrm{Su}[12]$} & $3 \mathrm{TC}(100)+\operatorname{Omt}\left(300^{\star}\right)$ & 30 & 12 & 91.23 & 66.67 & 86.67 \\
\hline & $3 \mathrm{TC}(100)$ & 30 & 12 & 68.26 & 43.33 & 63.33 \\
\hline \multirow{2}{*}{ Chen [13] } & $3 \mathrm{TC}(100)+\operatorname{Omt}(200)$ & 38 & 12 & - & 11 & 23 \\
\hline & $3 \mathrm{TC}(100)$ & 34 & 12 & - & 7 & 16 \\
\hline
\end{tabular}

\# The dosage unit is mg/day.

* The dosage of the former three months is $600 \mathrm{mg} /$ day by intravenous administration, and the dosage of the followed nine months is $300 \mathrm{mg} /$ day by oral administration.

-: the data were not reported in the original literatures.

the prices of such combinations are relatively cheap compared with the newly launched NAs. We recently noted that the clinical combination of oxymatrine, a phyto-derived drug, with 3TC could improve 3TC's curative effect with regard to $\mathrm{HBV}$ infection (Table 1) [6-13]. It has been reported that the combination of oxymatrine with 3TC could significantly increase the negative conversion rate of $\mathrm{HBV}$ DNA and hepatitis B e antigen ( $\mathrm{HBeAg}$ ) in patients compared with the solo use of 3TC. It was also reported that oxymatrine could also decrease the development of drug resistance to 3TC [14-17]. Furthermore, oxymatrine and its analog matrine (Figure 1), the two major alkaloid components in the root of Sophora flavescens Alt. (Kushen in Chinese, Figure 2), have been reported for their effectiveness in treating hepatocyte injury [18], liver fibrosis [19], and tissue inflammation [20]. Despite the clinical potential of this combination, which has been suggested previously in the literature, there is still a lack of experimental evidence in support of the superiority of the combination of 3TC with oxymatrine or matrine over 3TC alone. Therefore, in this study, we evaluated the anti$\mathrm{HBV}$ effects of the combination of matrine or oxymatrine with $3 \mathrm{TC}$ in the human HBV-transfected cell line HepG2 2.2.15 to illustrate the experimental basis for the combination therapy of natural products with NAs at the cellular level.

\section{Materials and Methods}

2.1. Drugs and Reagents. Matrine (purity: 99\%) and oxymatrine (purity: 99\%) were purchased from the National Institutes for Food and Drug Control, Beijing, China. 3TC (purity:
98\%) was provided by 302 Military Hospital, Beijing, China, and was used as the positive control. The drugs were dissolved in culture media at certain concentrations before use.

2.2. Cell Culture and Treatment. HepG2 2.2.15 cells, an HBVtransfect human HepG2 cell line, were provided by the Viral Research Lab at the Institute of Contagious Diseases in the 302 Military Hospital. The HepG2 2.2.15 cells were routinely cultured in Dulbecco's modified Eagle's medium (DMEM; Gibco, Langley, OK, USA) supplemented with 10\% (v/v) fetal calf serum (Gibco, Langley, OK, USA), antibiotics (100 units/mL penicillin/streptomycin) and $380 \mu \mathrm{g} / \mathrm{mL} \mathrm{G418}$ at $37^{\circ} \mathrm{C}$ in a humidified incubator with $5 \% \mathrm{CO}_{2}$.

HepG2 2.2.15 cells were plated at a density of $1 \times$ $10^{5}$ cells $/ \mathrm{mL}$ into 24 -well plates and incubated for $24 \mathrm{~h}$. Different concentrations of matrine $(100,200,400$, or $800 \mu \mathrm{g} / \mathrm{mL})$, oxymatrine $(100,200,400$, or $800 \mu \mathrm{g} / \mathrm{mL})$, and 3TC (30 or $100 \mu \mathrm{g} / \mathrm{mL}$ ) were added to the culture media. The cell wells were cultured for 9 days in the presence of the tested drugs, and the supernatants were collected every other day. The cell wells without drugs were set as the control. The concentrations of HBsAg, HBeAg, and HBV-DNA in the supernatant were determined on the 3 th, 6 th, and 9 th experimental day. The intracellular concentrations of HBVDNA were also determined on the 9th experimental day.

2.3. Cytotoxicity Assay. The in vitro drug cytotoxicity was assessed by an MTT (3-(4,5-dimethylthiazol-2yl)-2,5diphenyltetrazolium bromide) assay. Briefly, HepG2 2.2.15 cells $\left(1 \times 10^{5}\right.$ per well $)$ in the log phase were incubated into 


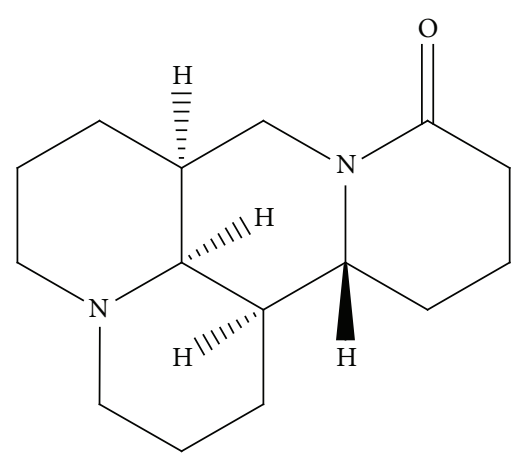

(a)

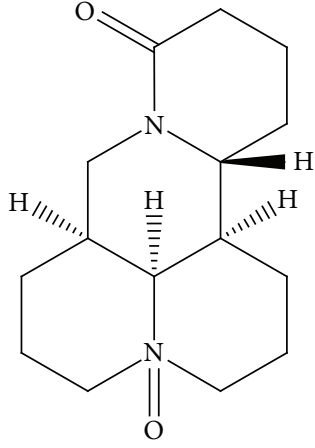

(b)

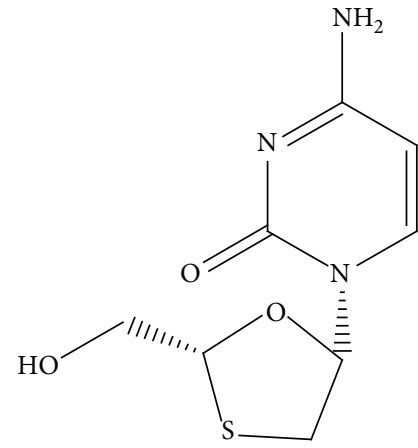

(c)

FIGURE 1: The chemical structures of matrine (a), oxymatrine (b), and lamivudine (c).

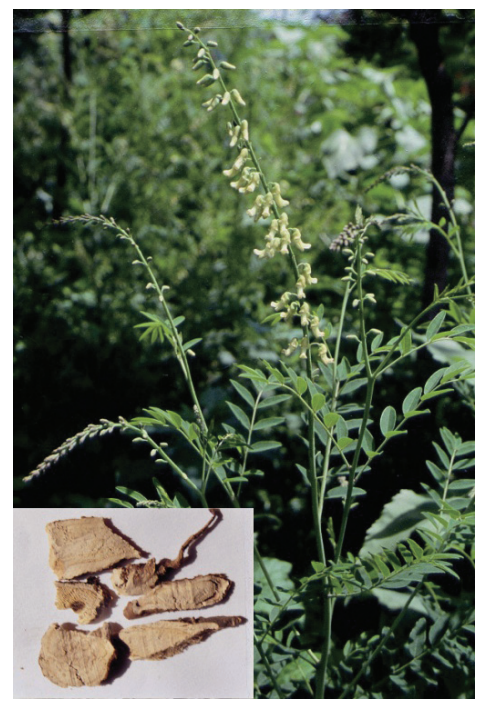

FIgURE 2: Photographs of Sophora flavescens Alt. and the dried root of the plant (left corner).

96-well plates. Different concentrations of 3TC, matrine, or oxymatrine were added into cell wells and cultured for 9 days to measure their cytotoxicity. After 9 days, MTT solution $(10 \mu \mathrm{L}$ at $5 \mathrm{mg} / \mathrm{mL})$ was added to each well and incubated for $4 \mathrm{~h}$. Then, the optical density (OD) value was read at $560 \mathrm{~nm}$ to measure the amount of cell proliferation using a plate reader (Synergy H1 Hybrid Reader, BioTek, Winooski, VT, USA). Each assay was repeated a minimum of three times. The cell viability was expressed as a percentage of the control.

2.4. Detection of $\mathrm{HBsAg}$ and $\mathrm{HBeAg}$. HBsAg and HBeAg in the culture media were determined using ELISA kits (Kehua Biological Technical Co. Ltd., China). The inhibition ratio was determined as follows:

( 1 - absorbance with drug/absorbance without drug) $\times$ $100 \%$. Each assay was repeated a minimum of three times.

2.5. Detection of $H B V-D N A$. HBV-DNA in culture supernatants on the 3th, 6th, and 9th days was quantitated by the real-time quantitative PCR analysis. The DNA in the culture supernatants $(100 \mu \mathrm{L}$, isolated at 5,000 rpm for 5 min in an Eppendorf microcentrifuge) was extracted using the QIAamp DNA Mini Kit (QIAGEN GmbH, Hilden,
Germany), following the manufacturer's recommendations. The PCR primers and probe were designed using Primer Express software (Applied Biosystems, Foster City, CA, USA). The primer sequences are shown in Table 2. Amplification was performed in a $50 \mu \mathrm{L}$ reaction mixture. After the preparation of the reaction mixtures in 96-well plates, the plates were centrifuged at $800 \mathrm{rpm}$ for $1 \mathrm{~min}$ in a Beckman GPKR swing rotor centrifuge. Amplification and detection were performed with an ABI Prism 7500 Sequence Detection System. The PCR protocol consisted of the following: (1) a single cycle of $2 \mathrm{~min}$ at $50^{\circ} \mathrm{C}$, followed by $10 \mathrm{~min}$ at $95^{\circ} \mathrm{C}$ and (2) 45 two-step cycles, with 1 cycle consisting of $15 \mathrm{sec}$ at $95^{\circ} \mathrm{C}$ and $60 \mathrm{sec}$ at $60^{\circ} \mathrm{C}$.

Data were calculated as the inhibition rate to control by the formula: (\% of control) $1-(\mathrm{ET}) /(\mathrm{EC}) \times 100 \%$, where ET and EC indicated the HBV-DNA expression of the tested drugs and the control without drugs, respectively.

\section{Results}

3.1. Cytotoxic Effects of Individual Drugs and Combinations. The viabilities of the HepG2.2.15 cells in the presence of various concentrations of matrine and oxymatrine were 
TABLE 2: The primers used for RT-PCR.

\begin{tabular}{lcc}
\hline Primer & Sequence & Product (bp) \\
\hline \multirow{3}{*}{ HBV } & F: ACT CGT GGT GGA CTT CTC TCA ATT & 136 \\
& R: CGC AGA CAC ATC CAG CGA TA \\
$\beta$-Actin & F: GGA AAT CGT GCG TGA CAT TAA G \\
& R: GCT CAT TGC CAA TGG TGA TG \\
\hline
\end{tabular}

examined with an MTT assay. The results showed that individual drugs at all the detected concentrations had low toxicity to HepG2.2.15 cells (Figure 3 ). Therefore, the nontoxic concentrations of oxymatrine and matrine to HepG2 2.2.15 cells were both $800 \mu \mathrm{g} / \mathrm{mL}$.

\subsection{Inhibitory Effects of Matrine and Lamivudine on $H B V$} Antigens and DNA. The results of the inhibitory effect of matrine, lamivudine, and their combinations are summarized in Figure 4. After 9 days of treatment, the 100 and $200 \mu \mathrm{g} / \mathrm{mL}(0.40$ and $0.81 \mu \mathrm{mol} / \mathrm{mL})$ dose of matrine as a single agent had weak inhibitory effects on the secretion of $\mathrm{HBeAg}$ into culture media ( $13 \%$ and $10 \%$, resp.), while the 400 and $800 \mu \mathrm{g} / \mathrm{mL}$ ( 1.61 and $3.22 \mu \mathrm{mol} / \mathrm{mL}$ ) dose had significant inhibitory effects ( $44 \%$ and $68 \%$, resp.). The $30 \mu \mathrm{g} / \mathrm{mL}(0.13 \mu \mathrm{mol} / \mathrm{mL})$ dose of $3 \mathrm{TC}$ as a single agent had no significant inhibitory effect on the secretion of $\mathrm{HBeAg}$, while the combinations of $3 \mathrm{TC}(30 \mu \mathrm{g} / \mathrm{mL})$ with matrine at 100,200 , or $400 \mu \mathrm{g} / \mathrm{mL}$ all showed significant inhibitory effects $(63 \%, 68 \%$, and $75 \%$, resp.) in a weak, time-dependent manner. Furthermore, the effects of such combinations were all superior to the effects of 3TC in solo use at $100 \mu \mathrm{g} / \mathrm{mL}$. The results are summarized in Figure 4.

When matrine was used solo below $400 \mu \mathrm{g} / \mathrm{mL}$, it showed a weak inhibitory effect on the secretion of HBsAg into culture media after 9 days of treatment. Moreover, the solo use of matrine at $800 \mu \mathrm{g} / \mathrm{mL}$ showed a significant inhibitory effect $(75 \%)$. It should be noted that the solo use of 3TC at 30 or $100 \mu \mathrm{g} / \mathrm{mL}$ showed weak inhibitory effects on the secretion of HBsAg, while the combinations of 3TC $(30 \mu \mathrm{g} / \mathrm{mL})$ with matrine at 100,200 , or $400 \mu \mathrm{g} / \mathrm{mL}$ showed enhanced, but also weak, inhibitory effects. The inhibitory effects on the secretion of HBsAg into culture media of matrine and 3TC, alone and in combination, decreased gradually with time.

After 9 days of treatment, the solo use of 400 or $800 \mu \mathrm{g} / \mathrm{mL}$ of matrine showed significant inhibitory effects on the secretion of HBV-DNA into culture media, equivalent to the effect of $3 \mathrm{TC}$ in solo use at $100 \mu \mathrm{g} / \mathrm{mL}$. The solo use of $3 \mathrm{TC}$ at $30 \mu \mathrm{g} / \mathrm{mL}$ showed weak inhibitory effects, while the combinations of 3TC $(30 \mu \mathrm{g} / \mathrm{mL})$ with matrine at $100 \mu \mathrm{g} / \mathrm{mL}, 200 \mu \mathrm{g} / \mathrm{mL}$, or $400 \mu \mathrm{g} / \mathrm{mL}$ all showed significant inhibitory effects in time- and dose-independent manners. Furthermore, the effects of such combinations were all greater than the effect of 3TC in solo use at $100 \mu \mathrm{g} / \mathrm{mL}$.

Either the solo use of matrine and 3TC or their combinations could significantly decrease the intracellular HBVDNA levels within a certain range of concentrations (Table 3). When matrine was used solo at $400 \mu \mathrm{g} / \mathrm{mL}$, it showed a weak

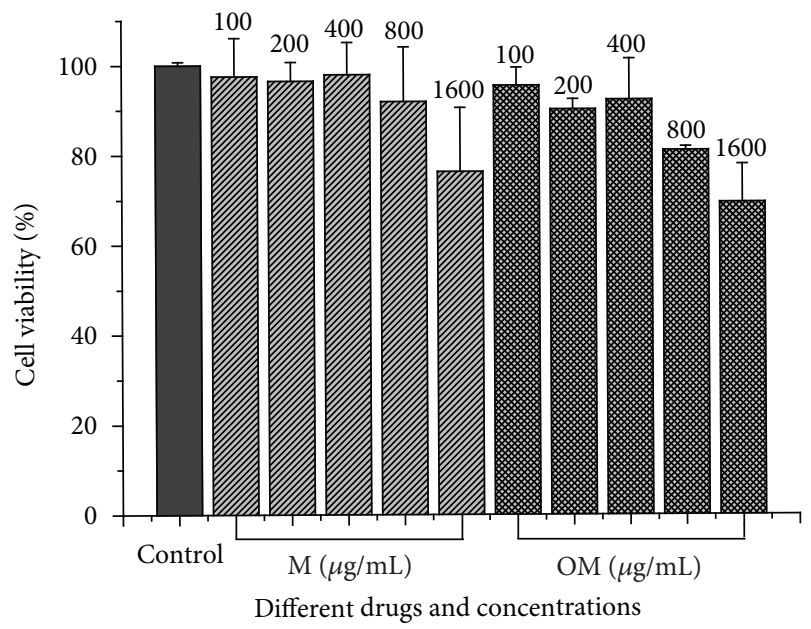

FIgure 3: The cytotoxicity of matrine and oxymatrine on HepG2 2.2.15 cells was evaluated by an MTT assay. The cell viability expressed as a percentage of control. The data are presented as the mean \pm S.D. $(n=3)$.

inhibitory effect on the intracellular HBV-DNA levels. Moreover, the solo use of matrine at $800 \mu \mathrm{g} / \mathrm{mL}$ showed a significant inhibitory effect (94\%), equivalent to the effect of $3 \mathrm{TC}$ in solo use at $100 \mu \mathrm{g} / \mathrm{mL}$. The solo use of $3 \mathrm{TC}$ at $30 \mu \mathrm{g} / \mathrm{mL}$ also possessed an inhibitory effect of $79 \%$; the combinations of $3 \mathrm{TC}(30 \mu \mathrm{g} / \mathrm{mL})$ with matrine at $100 \mu \mathrm{g} / \mathrm{mL}, 200 \mu \mathrm{g} / \mathrm{mL}$, or $400 \mu \mathrm{g} / \mathrm{mL}$ all showed strong inhibitory effects (>94\%), which is equivalent to the solo use of $3 \mathrm{TC}$ at $100 \mu \mathrm{g} / \mathrm{mL}$.

3.3. Inhibitory Effects of Oxymatrine and Lamivudine on $\mathrm{HBV}$ Antigens and DNA. The results of the inhibitory effect of oxymatrine, lamivudine, and their combinations are summarized in Figure 5. After 9 days of treatment, the 100 and $200 \mu \mathrm{g} / \mathrm{mL}(0.38$ and $0.76 \mu \mathrm{mol} / \mathrm{mL})$ doses of oxymatrine as a single agent had a weak inhibitory effect on the secretion of HBeAg into culture media (31\% and $36 \%$, resp.). The 400 and $800 \mu \mathrm{g} / \mathrm{mL}(1.52$ and $3.03 \mu \mathrm{mol} / \mathrm{mL})$ doses of oxymatrine also had evident inhibitive effects on the secretion of $\mathrm{HBeAg}$ (54\% and $61 \%$, resp.), which were superior to the effect of $100 \mu \mathrm{g} / \mathrm{mL}(0.43 \mu \mathrm{mol} / \mathrm{mL})$ of $3 \mathrm{TC}(45 \%)$. The $30 \mu \mathrm{g} / \mathrm{mL}$ $(0.13 \mu \mathrm{mol} / \mathrm{mL})$ dose of $3 \mathrm{TC}$ as a single agent had no significant inhibitory effect on the secretion of $\mathrm{HBeAg}$, while the combinations of $3 \mathrm{TC}(30 \mu \mathrm{g} / \mathrm{mL})$ with oxymatrine at 100 , 200 , or $400 \mu \mathrm{g} / \mathrm{mL}$ all showed significant inhibitory effects $(63 \%, 68 \%$, and $75 \%$, resp.) in a time-dependent and weak dose-dependent manner. Additionally, the effects of such 
Inhibition (\%)
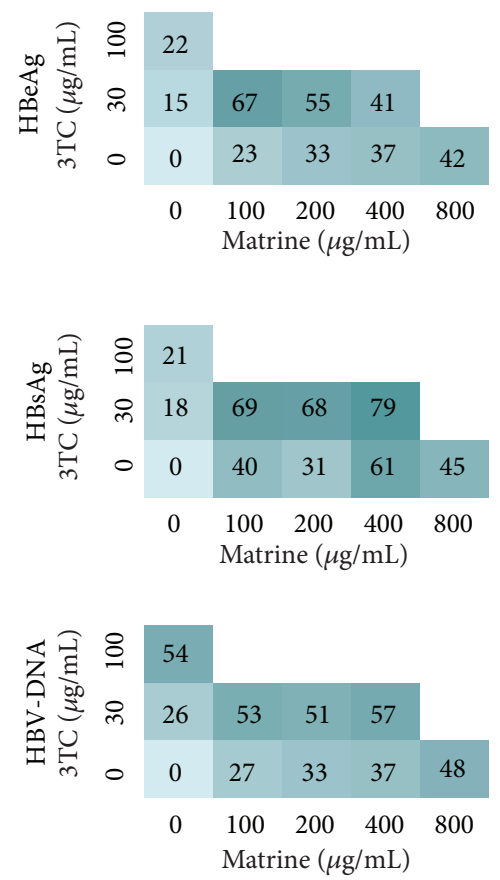

$3 \mathrm{~d}$
Inhibition (\%)
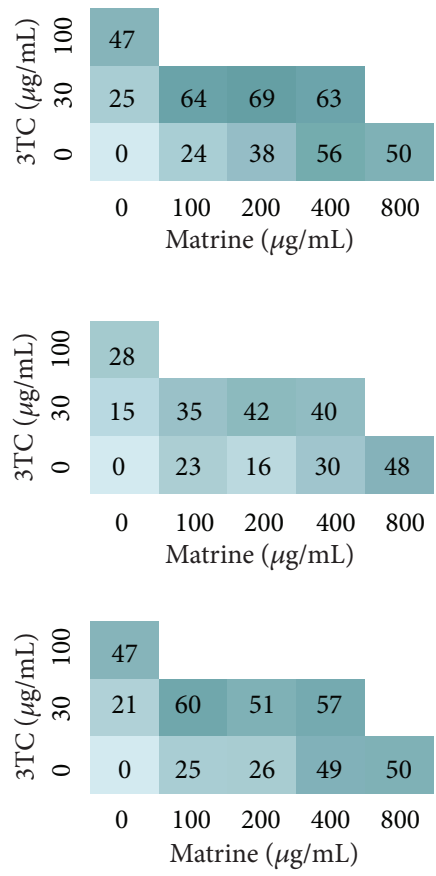

$6 \mathrm{~d}$
Inhibition (\%)
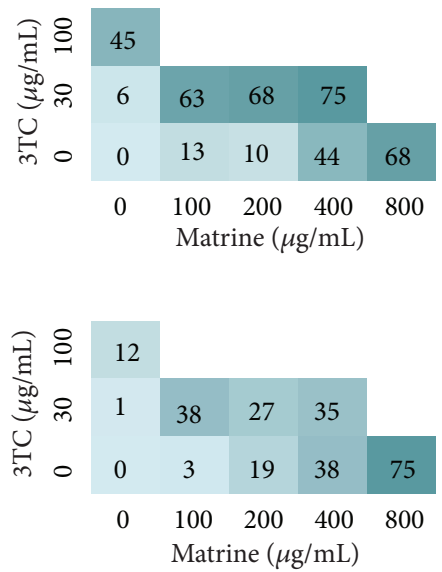

50

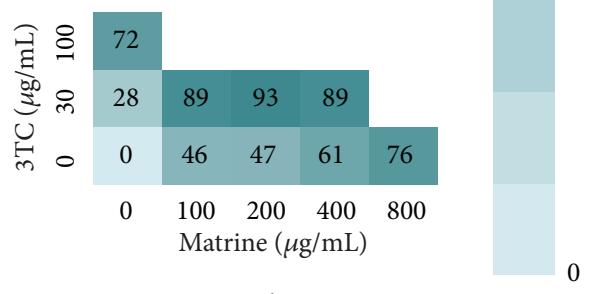

$9 \mathrm{~d}$

FIGURE 4: The anti-HBV activity matrices of 3TC, matrine, and their combinations in different concentrations. The average inhibitory effects $(\%, n=3)$ on the secretion of HBsAg, HBeAg, and HBV-DNA are labeled in the squares for each pair of combinations. The colors of the squares visually indicate the inhibitory level.

TABLE 3: The inhibition rates of lamivudine combined with matrine or oxymatrine to the intracellular concentrations of HBV-DNA on the 9th experimental day.

\begin{tabular}{|c|c|c|c|}
\hline Drugs $(\mu \mathrm{g} / \mathrm{mL})$ & Inhibition (\%) & Drugs $(\mu \mathrm{g} / \mathrm{mL})$ & Inhibition (\%) \\
\hline $3 \mathrm{TC}(30)$ & 79 & & \\
\hline $3 \mathrm{TC}(100)$ & 97 & & \\
\hline Matrine (100) & - & Oxymatrine (100) & - \\
\hline Matrine (200) & 39 & Oxymatrine (200) & - \\
\hline Matrine (400) & 59 & Oxymatrine (400) & 20 \\
\hline Matrine (800) & 94 & Oxymatrine (800) & 71 \\
\hline Matrine + 3TC $(100+30)$ & 94 & Oxymatrine + 3TC $(100+30)$ & 98 \\
\hline Matrine + 3TC $(200+30)$ & 95 & Oxymatrine + 3TC $(200+30)$ & 95 \\
\hline Matrine + 3TC $(400+30)$ & 95 & Oxymatrine + 3TC $(400+30)$ & 98 \\
\hline
\end{tabular}

-: the values are below zero.

combinations were all better than the effect of 3TC in solo use at $100 \mu \mathrm{g} / \mathrm{mL}$.

Oxymatrine had weak inhibitory effects on the secretion of HBsAg into culture as a single agent at all the tested concentrations $(100,200,400$, and $800 \mu \mathrm{g} / \mathrm{mL})$ after 9 days of treatment. The solo use of 3TC (30 or $100 \mu \mathrm{g} / \mathrm{mL})$ had a weak inhibitory effect ( $1 \%$ and $12 \%$, resp.); the combinations of $3 \mathrm{TC}(30 \mu \mathrm{g} / \mathrm{mL})$ with oxymatrine at 100,200 , or $400 \mu \mathrm{g} / \mathrm{mL}$ also showed evident inhibitory effects $(41 \%, 38 \%$, and $41 \%$, resp.).

When oxymatrine was used solo at the concentrations of 400 or $800 \mu \mathrm{g} / \mathrm{mL}$, it showed significant inhibitory effects on the secretion of HBV-DNA into culture media after 9 days of treatment. Such effects are equivalent to the effect of 3TC in solo use at $100 \mu \mathrm{g} / \mathrm{mL}$. 3TC, as a single agent at $30 \mu \mathrm{g} / \mathrm{mL}$, also showed a weak inhibitory effect on extracellular HBVDNA concentrations; the combinations of 3TC $(30 \mu \mathrm{g} / \mathrm{mL})$ with oxymatrine $(100,200$, or $400 \mu \mathrm{g} / \mathrm{mL})$ all showed significant inhibitory effects. Additionally, the effects of such combinations were all superior to the effect of 3TC in solo use at $100 \mu \mathrm{g} / \mathrm{mL}$.

The intracellular HBV-DNA inhibition rate of oxymatrine as a single agent at $800 \mu \mathrm{g} / \mathrm{mL}$ was $71 \%$, while its effects below $400 \mu \mathrm{g} / \mathrm{mL}$ were weak (Table 3 ). The solo use 
Inhibition (\%)
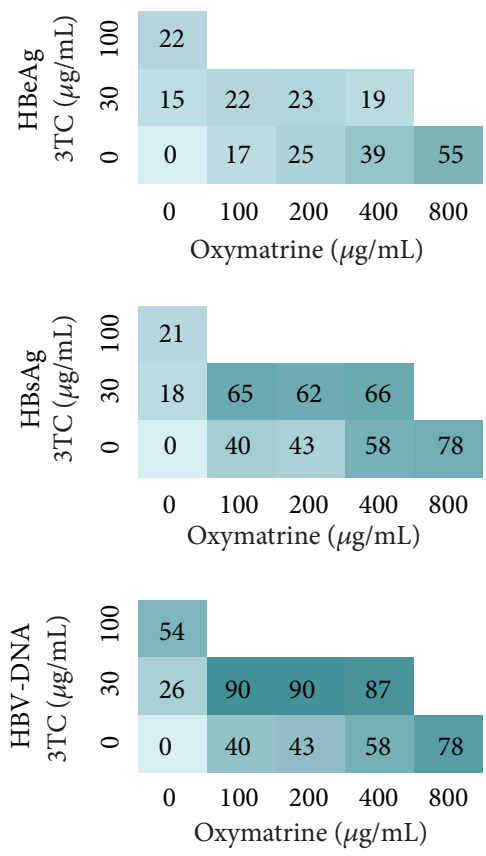

$3 \mathrm{~d}$
Inhibition (\%)
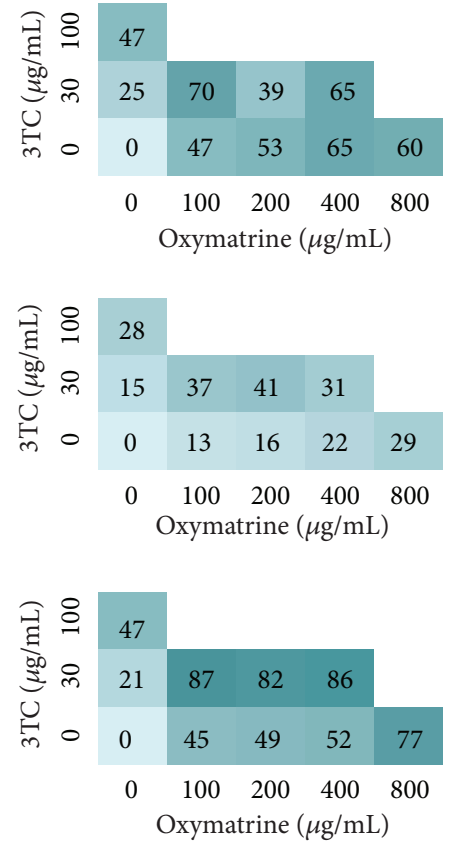

$6 \mathrm{~d}$
Inhibition (\%)
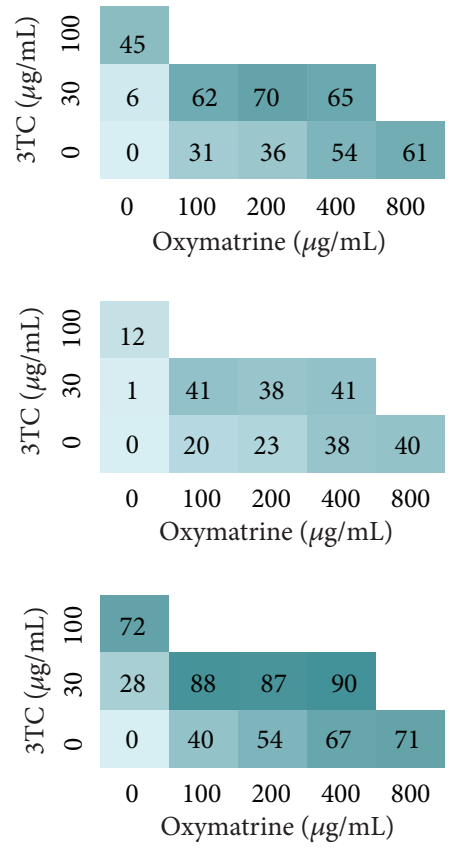

$9 \mathrm{~d}$

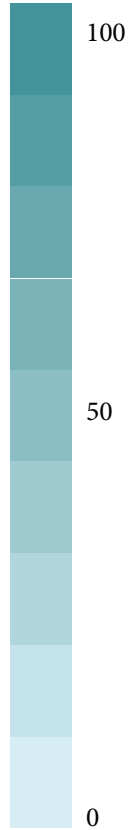

FIgURE 5: The anti-HBV activity matrices of 3TC, oxymatrine, and their combinations in different concentrations. The average inhibitory effects $(\%, n=3)$ on the secretion of HBsAg, HBeAg, and HBV-DNA are labeled in the squares for each pair of combinations. The colors of the squares visually indicate the inhibitory level.

of $3 \mathrm{TC}$ at $30 \mu \mathrm{g} / \mathrm{mL}$ possessed an inhibitory effect of $79 \%$. The combinations of $3 \mathrm{TC}(30 \mu \mathrm{g} / \mathrm{mL})$ with oxymatrine at 100,200 , or $400 \mu \mathrm{g} / \mathrm{mL}$ all showed strong inhibitory effects (>95\%), which is equivalent to the solo use of 3TC at $100 \mu \mathrm{g} / \mathrm{mL}$.

\section{Discussion}

Traditional Chinese medicine is now widely used to treat hepatitis B in China as well as other areas in the world. Some believe that TCM may offer good therapeutic candidates with special antiviral characteristics to treat HBV infection, while others argue on its scientific merit. Many TCM and related active compounds have been reported to have potent anti-HBV activities, including Phyllanthus urinaria L., Salvia miltiorrhiza Bge., Rheum palmatum L., Astragalus membranaceus (Fisch.) Bge., oxymatrine, artemisinin, artesunate, and wogonin [21]. Although there are no effective anti-HBV compounds from TCM being successfully developed into commercial drugs to date, the combination of TCM with NAs represents a potential anti-HBV therapy for future utilization in clinical practice within China. The therapeutic combination of TCM or its components with 3TC is increasingly being reported in the literature [22, 23]. Many researches show that the combination of oxymatrine with 3TC could significantly increase the effect of anti-HBV in chronic hepatitis $\mathrm{B}$ treatment. We also found that combinations of oxymatrine together with 3TC had a beneficial clinical response and significantly reduced the drug resistance of
3TC in our hospital (unpublished data). Thus, we have a great interest in the examination of the scientific evidence regarding the therapeutic potential of the combination of matrine or oxymatrine together with 3TC in vitro.

The results in this study showed that $3 \mathrm{TC}$ at $100 \mu \mathrm{g} / \mathrm{mL}$ $(0.44 \mu \mathrm{mol} / \mathrm{mL})$ had a strong inhibitory effect on either the extracellular or the intracellular levels of HBV-DNA, while its inhibitory effect was weak at $30 \mu \mathrm{g} / \mathrm{mL}$. 3TC $(100 \mu \mathrm{g} / \mathrm{mL})$ also showed weak inhibitory effects on the extracellular levels of HBeAg and HBsAg. When the concentration of matrine or oxymatrine was below $100 \mu \mathrm{g} / \mathrm{mL}$, their inhibitory effect was minimal. In contrast, the combination of $3 \mathrm{TC}(30 \mu \mathrm{g} / \mathrm{mL})$ with oxymatrine $(100 \mu \mathrm{g} / \mathrm{mL})$ or matrine $(100 \mu \mathrm{g} / \mathrm{mL})$ showed significant inhibitory effects. The inhibitory effects of such combinations on either the extracellular or intracellular levels of HBV-DNA, HBeAg, and HBsAg were higher than the effect of the solo use of each compound at tested concentrations; furthermore, the effects were higher than or equivalent to the effect of the solo use of 3TC at $100 \mu \mathrm{g} / \mathrm{mL}$ (Figures 4 and 5, Table 3). The results illustrate the synergistic potential of the combination of matrine or oxymatrine with 3TC. However, the synergistic effect we discussed in this study is preliminary and superficial, and this result should be further confirmed by the strict evaluation method (e.g., fractional inhibitory concentration index (FICI)) for synergistic effects. The results reported in the aforementioned clinical literatures led us to believe that our results provide experimental evidence at the cellular level that supports the superiority of the combination of $3 \mathrm{TC}$ with oxymatrine or matrine. 


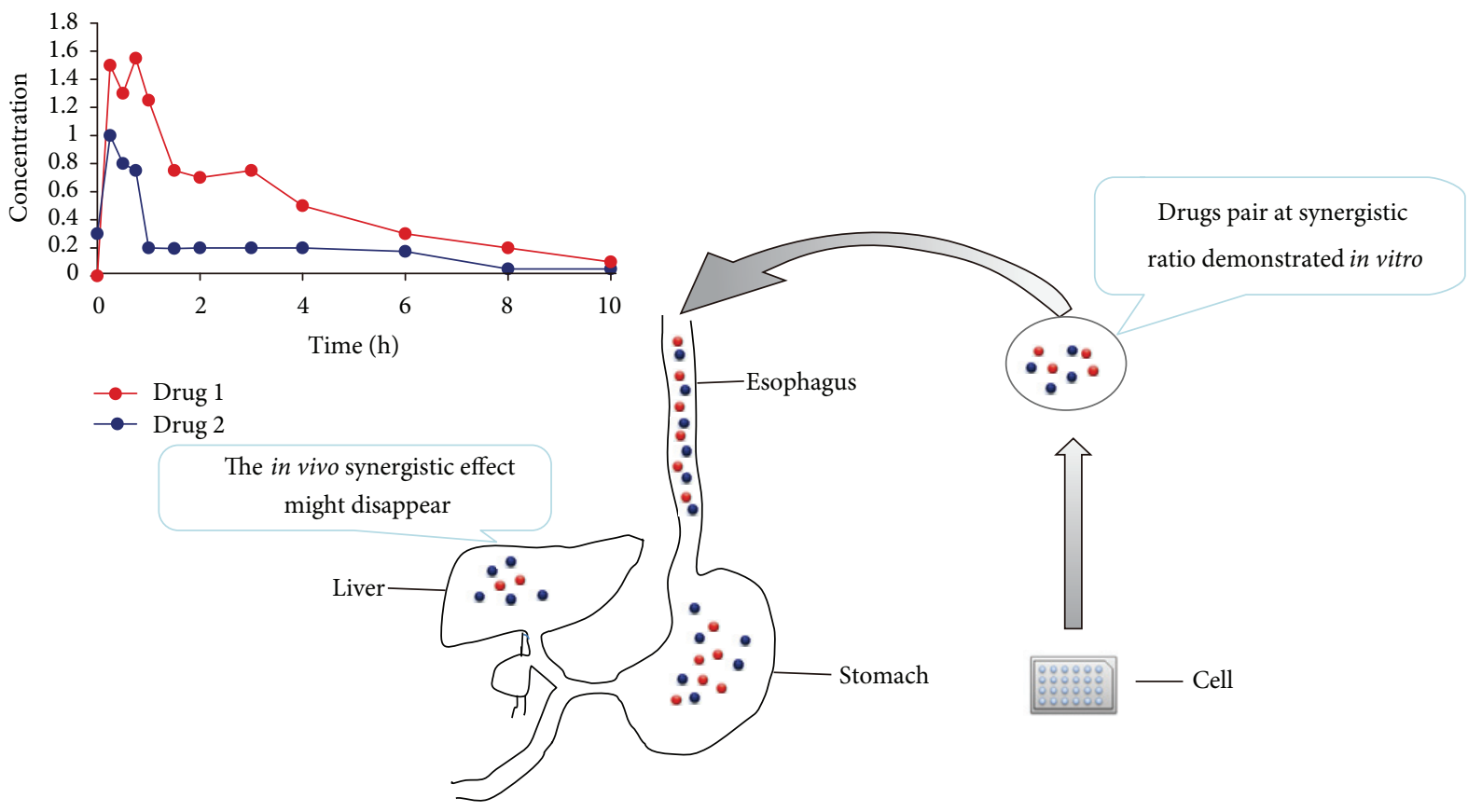

FIGURE 6: The synergistic effect of the two drugs might be influenced by the metabolic course. When a pair of drug compounds at the desired ratio (demonstrated for synergistic effect in vitro) was orally administered into body, the metabolic processes of drug absorption, distribution, metabolism, and excretion will change the ratio of the drugs. As a consequence, the in vivo synergistic effects of the drug pair may disappear if the drug pair can only possess a synergistic ratio within a narrow range.

Another phenomenon that piqued our interest is the dose-effect relationships of the combinations. We noted that the combinations of $3 \mathrm{TC}(30 \mu \mathrm{g} / \mathrm{mL})$ with matrine or oxymatrine at different concentrations from $100 \mu \mathrm{g} / \mathrm{mL}$ to $400 \mu \mathrm{g} / \mathrm{mL}$ showed a weak, dose-dependent anti-HBV effect. That is, the concentration of $100 \mu \mathrm{g} / \mathrm{mL}$ of matrine or oxymatrine would be enough to produce synergistic effects with 3TC. Furthermore, we can conclude that the synergistic effect between 3TC and matrine or oxymatrine is nearly steady over a relatively wide range of doses, at least from $1: 1$ to $1: 4$. This feature is very important for the clinical application of combinatorial therapy. Different drugs have differential pharmacokinetic characteristics that are time dependent and tissue specific. Although we can combine two synergistic drugs at the correct proportion in one capsule, the two drugs will not achieve the expected proportion in the blood, tissue, cell, or target. Their proportion will certainly vary over time (Figure 6). If the range of the synergistic proportion is narrow, it could be anticipated that the combination will not achieve expected in vivo synergistic effects, a phenomenon which has been confirmed in vitro. A study of antitumor combination drugs, for example, confirmed this assumption [24]. This study reports two drugs that possess a synergistic effect within a narrow proportion in vitro, while the combination had weak effects in vivo. When the proportion of the two drugs was purposely controlled in the tumor tissue through a pharmaceutical approach, the combination regained the synergistic effect in vivo, similar to the results observed in vitro. Therefore, a wide range of synergistic proportions is more advantageous than a narrow range for combinatorial therapy due to pharmacokinetic concerns. It may also be a valuable feature in that there is a relatively wide range of synergetic proportions of 3TC with matrine or oxymatrine for clinical combinatorial therapy. However, the pharmacokinetic differences between 3TC and matrine or oxymatrine have not been fully addressed and require further investigation.

\section{Conflict of Interests}

The authors declare that they have no competing interests.

\section{Author's Contribution}

Z.-J. Ma and Q. Li contributed equally to this work.

\section{Acknowledgments}

The authors acknowledge Professor Juan Wang for her useful advices to their study. This work was funded by the National Natural Science Foundation of China (nos. 30973947, 81274026, and 81173571), the National Industry Program of China (nos. 200807020 and 201207002), and by the National Key Technology R\&D Program (nos. 2012BAI29B02 and 2012ZX10005010-002-002).

\section{References}

[1] A. S. F. Lok and B. J. McMahon, "Chronic hepatitis B: update 2009,” Hepatology, vol. 50, no. 3, pp. 661-662, 2009.

[2] M. Morgan and E. B. Keeffe, "Diagnosis and treatment of chronic hepatitis B: 2009 update," Minerva Gastroenterologica e Dietologica, vol. 55, no. 1, pp. 5-22, 2009. 
[3] European Association for the Study of the Liver, "EASL clinical practice guidelines: management of chronic hepatitis B virus infection," Journal of Hepatology, vol. 57, no. 1, pp. 167-185, 2012.

[4] J. Wiegand, F. van Bömmel, and T. Berg, "Management of chronic hepatitis B: status and challenges beyond treatment guidelines," Seminars in Liver Disease, vol. 30, no. 4, pp. 361-377, 2010

[5] Y. F. Liaw, "Antiviral therapy of chronic hepatitis B: opportunities and challenges in Asia," Journal of Hepatology, vol. 51, no. 2, pp. 403-410, 2009.

[6] L. Song, "Clinical observation of treating patient with chronic hepatitis B by lamivudine combined with oxymatrine injection," Journal of Medical Forum, vol. 25, pp. 11-13, 2004.

[7] R. Fan, "Clinical study of treating patient with chronic hepatitis B by lamivudine combined with oxymatrine," Chinese Medicine Modern Distance Education of China, vol. 6, no. 1, pp. 72-73, 2008.

[8] J. Duan, "Combined application of oxymatrine and lamivudine in treating 60 cases of chronic hepatitis B clinical," Journal of the Fourth Military Medical University, vol. 25, no. 4, 2004.

[9] C. Zhang, "Combined application of oxymatrine and lamivudine in treating 62 cases of chronic hepatitis B," Clinical Medical Engineering, vol. 19, no. 6, pp. 935-936, 2012.

[10] K. Xie, "Analysis of clinical therapeutic effect 120 cases of treating patient with chronic hepatitis B by oxymatrine and lamivudine," CJGMTCM, vol. 22, no. 10, pp. 82-83, 2007.

[11] Z. Liu, "Therapeutic effect of oxymatrineinjection combined lamivudine for chronic hepatitis B," Journal of Xinxiang Medical College, vol. 20, no. 1, pp. 41-42, 2003.

[12] G. Su, "Therapeutic effect of combined lamivudine and oxymatrinefor chronic hepatitis B," Clinical Medicine, vol. 25, no. 12, pp. 62-64, 2005.

[13] W. Chen, "Clinical observation of treating patients for 38 cases with chronic hepatitis B by lamivudine combined with oxymatrine," China Journal of Modern Medicine, vol. 16, no. 10, pp. 62-63, 2009.

[14] W. Wenqi and C. Yunqiao, "Clinical study of lamivudine combined with kurorinone in the treatment of chronic hepatitis B," Journal of Clinical and Experimental Hepatology, vol. 8, no. 2, pp. 83-84, 2005.

[15] L. Jia and L. Shu-ren, "Therapeutic effect of oxymatrine combined with laminudine in treating patients with chronic hepatits B," Tianjin Journal of Traditional Chinese Medicine, vol. 24, no. 2, pp. 107-109, 2007.

[16] Z. xiangguo, "Clinical study of lamivudine combined with matrine in the treatment of chronic hepatitis B," China Clinical Practical Medicine, vol. 4, no. 15, pp. 143-144, 2009.

[17] G. xiang, "Clinical study of lamivudine combined with matrine in the treatment of chronic hepatitis B," Progress in Modern Biomedicine, vol. 6, no. 7, pp. 88-89, 2006.

[18] X. Gui-ping, "Study on the protective effect of matrine on immune liver injury in rats," Lishizhen Medicine and Materia Medica Research, vol. 6, no. 13, 2007.

[19] J. P. Zhang, M. Zhang, J. P. Zhou et al., "Antifibrotic effects of matrine on in vitro and in vivo models of liver fibrosis in rats," Acta Pharmacologica Sinica, vol. 22, no. 2, pp. 183-186, 2001.

[20] Z. L. Hu, J. P. Zhang, D. H. Qian et al., "Effects of matrine on mouse splenocyte proliferation and release of interleukin-1 and -6 from peritoneal macrophages in vitro," Acta Pharmacologica Sinica, vol. 17, no. 3, pp. 259-261, 1996.
[21] X. Cui, Y. Wang, N. Kokudo, D. Fang, and W. Tang, "Traditional Chinese medicine and related active compounds against hepatitis B virus infection," Bioscience Trends, vol. 4, no. 2, pp. 39-47, 2010.

[22] T. guangjun, F. tianbao, T. mingzeng, and W. xinhua, "Shortterm effect of phyllanthus compound and lamivuding in treating chronic hepatitis B: an observation of 30 cases," Journal of Guangzhou University of Traditional Chinese Medicine, vol. 21, no. 4, pp. 257-259, 2004.

[23] H. xiaoquan, Y. decai, and W. hongjing, "Clinical study of phyllanthus compound and lamivuding in treating chronic hepatitis B: an observation of 80 cases," Chinese Journal of Experimental Traditional Medical Formulae, vol. 9, no. 6, pp. 48-49, 2003.

[24] L. D. Mayer and A. S. Janoff, "Optimizing combination chemotherapy by controlling drug ratios," Molecular Interventions, vol. 7, no. 4, pp. 216-223, 2007. 


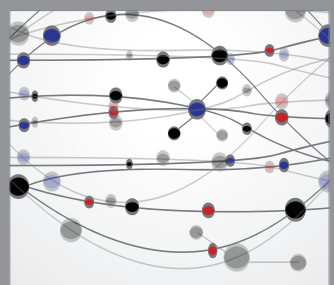

The Scientific World Journal
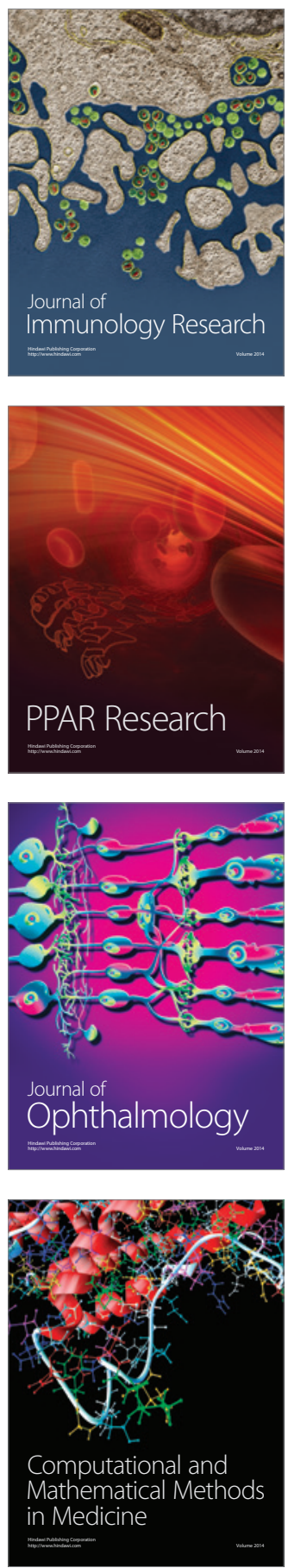

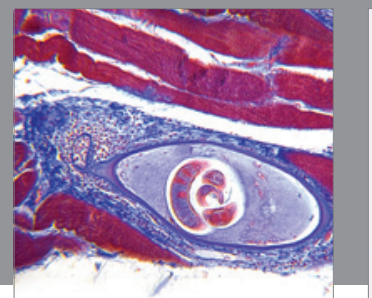

Gastroenterology

Research and Practice
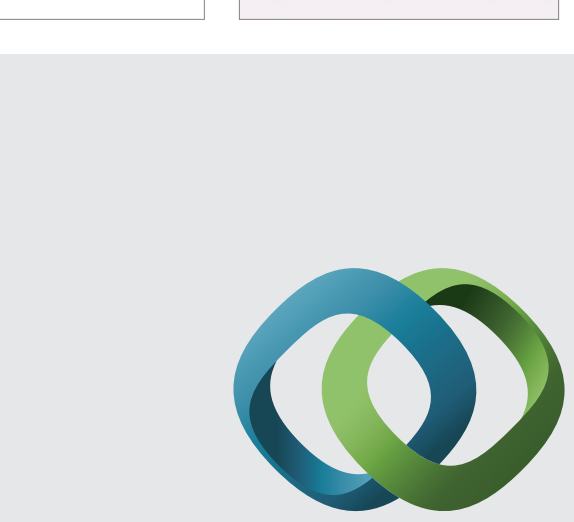

\section{Hindawi}

Submit your manuscripts at

http://www.hindawi.com
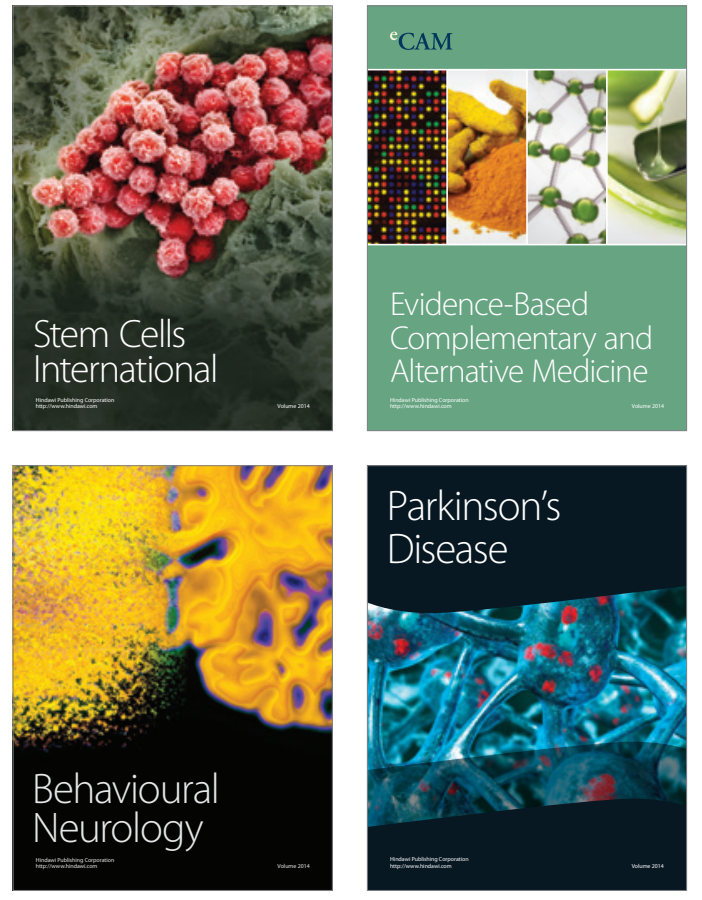
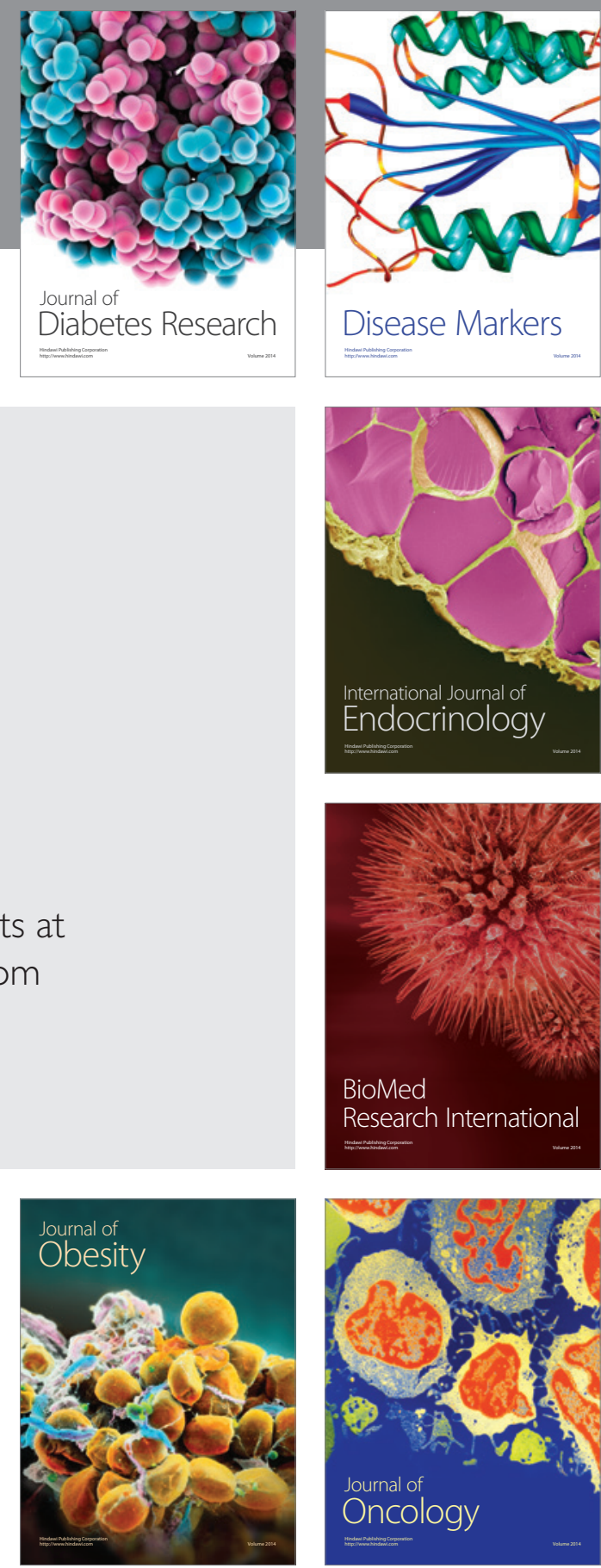

Disease Markers
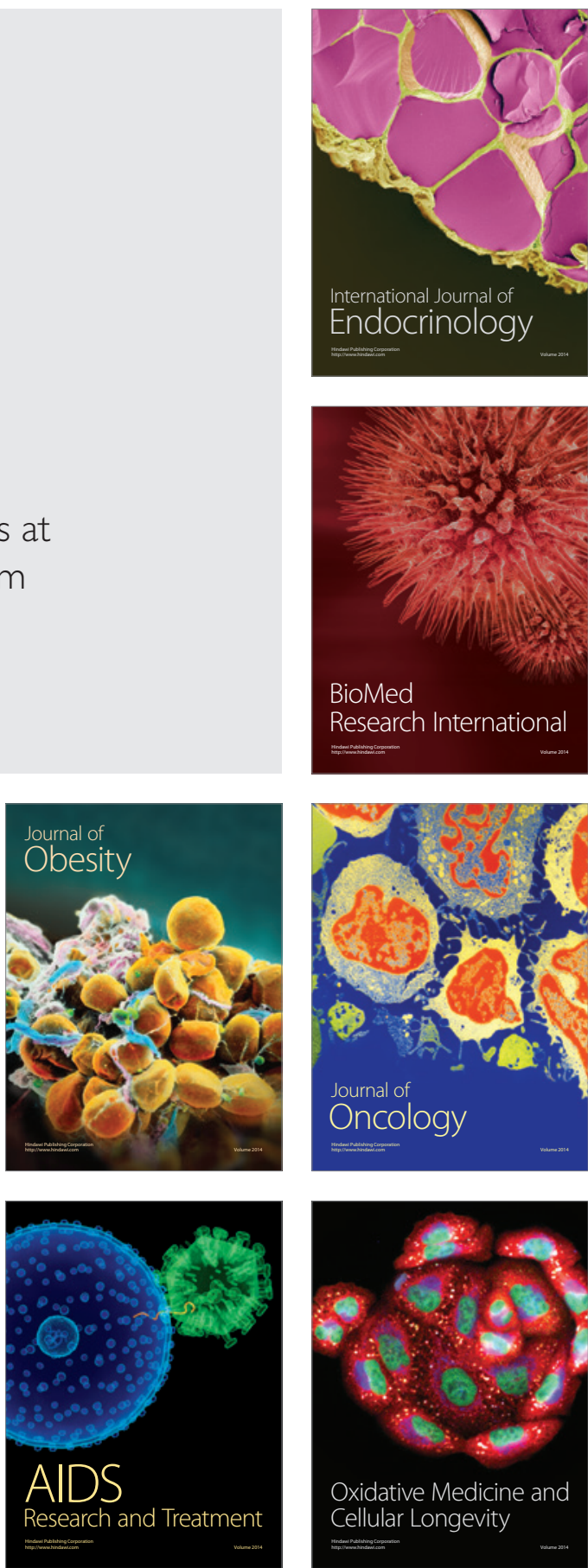